\title{
Common bile duct stenting for choledocholithiasis: a district general hospital experience
}

\author{
D J Bowrey, L J Fligelstone, A Solomon, G Thomas, A A Shandall
}

\begin{abstract}
Summary
The favoured treatment of common bile duct stones is endoscopic sphincterotomy and stone extraction. The management of those cases where duct clearance is not possible is controversial. At our institution it has been policy to insert an endoluminal stent. We report a retrospective review of the outcome of patients stented for common bile duct stones. The study population was 14 men and 22 women, with a median age of 73 years (range 23-89 years). Treatment-related morbidity was seen in nine patients (25\%), comprising cholangitis (5), pancreatitis (3), and cholecystitis (1). Three of these patients died; all were over the age of 75 years and had been stented on a long-term basis. These data suggest that endobiliary stents can be employed with an acceptable complication rate. We suggest that patients under the age of 75 years be stented only as a temporising measure, but that patients over 75 years or those unfit on physiological grounds can be stented on a long-term basis as definitive treatment.
\end{abstract}

Keywords: common bile duct calculi; stents

Up to $15 \%$ of patients with cholelithiasis are affected by stones within the common bile duct. ${ }^{1}$ Prior to the advent of endoscopic retrograde cholangiopancreatography (ERCP) the management comprised surgical exploration of the common bile duct. ${ }^{2}$ Many of these patients are elderly and have comorbidity, making surgery and anaesthesia hazardous. ${ }^{3-8}$ Further, these patients are compromised as a result of sepsis and jaundice secondary to the underlying biliary tract obstruction.

Currently, the favoured therapeutic modality is endoscopic sphincterotomy and stone extraction. Ideally, the common bile duct should be left free of stones at the initial endoscopic procedure. This is achieved in over $80 \%$ of patients. $^{9-12}$ Retained stones following the initial endoscopic procedure are associated with a three-fold excess of complications. ${ }^{13-15}$ Management of such cases of incomplete common bile duct clearance is controversial. At our institution it has been policy to employ endoluminal stents in such cases. The study was a retrospective review of the outcome of patients stented for common bile duct stones.

\section{Methods}

A retrospective analysis of patients stented for choledocholithiasis between January 1992 and November 1994 was undertaken. Patients were identified from a computerised database listing all endoscopic procedures, and the case notes reviewed. All patients underwent abdominal ultrasound examination prior to ERCP, which was performed using an Olympus T20 side-viewing duodenoscope and Niopam 200 contrast agent. Three doses of intravenous cephradine $(500 \mathrm{mg})$ were given as antibiotic prophylaxis. Stone extraction was by a balloon or Dormia basket technique. Correct stent deployment was confirmed by fluoroscopy. The stents used were either 7 French Pigtail stents or 10 French straight stents (Schneider, Middlesex, UK). Following discharge from hospital, patients were reviewed in the out-patient clinic for a minimum of six months. Statistical analysis was performed using Fisher's exact test and the Mann-Whitney U test, with significance taken at the $5 \%$ level.

\section{Results}

During the study period 204 ERCPs for choledocholithiasis were performed. Duct clearance was achieved at the initial procedure in 165 patients $(81 \%)$. In 39 patients this was not feasible and a stent was deployed. Complete data were available on 36 of these 39 patients. The study group comprised 14 men and 22 women, with a median age of 73 years (range 23-89). Fifteen of the 36 (42\%) were over the age of 75 . The median follow-up time for the group was 12.5 months (range 0.5-36) with stents being left in-situ for a median time of 5 months (range $0.5-36$ ). The minimum follow-up time was 6 months (excepting those patients dying prior to this time). Twenty-three of the patients had common bile duct stones of $1.0 \mathrm{~cm}$ or greater diameter, and in 18 patients the duct contained multiple stones.

Based upon the intention of treatment (see table 1), 18 patients had a stent placed as a temporising measure. In the remaining 18 patients the stent was deployed as definitive therapy; these patients were considered 
Table 1 Patient characteristics by intention of stenting

\begin{tabular}{llll}
\hline Intention of stenting: & $\begin{array}{l}\text { Temporising } \\
(n=18)\end{array}$ & $\begin{array}{l}\text { Definitive } \\
(n=18)\end{array}$ & \\
\hline Male:female & $11: 7$ & $3: 15$ & $\mathrm{p}<0.05$ \\
Median age in years (range) & $66(23-83)$ & $81(70-89)$ & $\mathrm{p}<0.05$ \\
Prior cholecystectomy & $5(28 \%)$ & $4(22 \%)$ & $\mathrm{p}=0.70$ \\
Duct clearance achieved & $10(56 \%)$ & $0(0 \%)$ & $\mathrm{p}<0.05$ \\
Surgery undertaken & $15(83 \%)$ & $0(0 \%)$ & $\mathrm{p}<0.05$ \\
Treatment-related morbidity & $5(28 \%)$ & $4(22 \%)$ & $\mathrm{p}=0.70$ \\
Treatment-related mortality & $0(0 \%)$ & $3(17 \%)$ & $\mathrm{p}=0.07$ \\
Unrelated causes mortality & $0(0 \%)$ & $4(22 \%)$ & $\mathrm{p}<0.05$ \\
Median duration of stenting (months) (range) & $2.5(1-26)$ & $10.5(0.5-36)$ & $\mathrm{p}<0.05$ \\
Median duration of follow-up (months) (range) & $20(6-34)$ & $10.5(0.5-36)$ & $\mathrm{p}=0.36$ \\
\hline
\end{tabular}

Table 2 Operations undertaken during period of study

\begin{tabular}{ll}
\hline Procedure & Number \\
\hline Cholecystectomy* & 7 \\
Cholecystectomy and common bile duct exploration & 5 \\
Common bile duct exploration & 3
\end{tabular}

«Until Autumn 1992 it was usual practice to perform open cholecystectomy; thereafter laparoscopic cholecystectomy was the operation employed.

Table 3 Early and late complications following stenting

\begin{tabular}{llllll}
\hline \multirow{2}{*}{$\begin{array}{l}\text { Intention of } \\
\text { stenting: }\end{array}$} & \multicolumn{2}{l}{ Temporising $(n=18)$} & & \multicolumn{2}{l}{ Definitive $(n=18)$} \\
\cline { 2 - 3 } \cline { 5 - 6 } & Early & Late $(>72 h)$ & & Early & Late $(>72 h)$ \\
\hline Cholecystitis & 0 & 1 & 0 & 0 \\
Cholangitis & 1 & 1 & & 0 & 3 (2 deaths) \\
Pancreatitis & 0 & 2 & & 1 death) & 0 \\
\hline
\end{tabular}

unsuitable for surgery on the basis of coexisting medical conditions or advanced age. The commonest presenting symptoms and signs were pain (30 patients, $86 \%$ ) and jaundice (29 patients, $80 \%$ ). Seven patients had previously undergone cholecystectomy (median interval 21 years, range 6-40). Fifteen patients $(42 \%)$ subsequently underwent surgical intervention during the study period (table 2). Effective bile drainage, denoted by a return to normal liver function test was achieved in all but one patient. Table 3 lists the complications following stenting. The only significant risk factor for the development of complications was male gender $(p<0.05)$. None of the following was associated with an elevated risk for the development of complications: the presence of an in-situ gallbladder, age, intention of stenting, or performance of endoscopic sphincterotomy. There were

1 Way L, Sleisinger M. Biliary obstruction, cholangitis and choledocholithiasis. In: Sleisinger $M$, Fordtran J, eds, Gastrointestinal diseases, 4th edn. Philadelphia: WB Saunders, 1989; pp 1714-28.

2 Peters R, Macmathuna P, Lombard M, Karani J, Westaby D. Management of common bile duct stones with a biliary endoprosthesis. Report on 40 cases. Gut 1992;33: $1412-5$

3 Kubota Y, Takaoka M, Fujimura K, et al. Endoscopic endoprosthesis for large stones in the common bile duct. Intern Med 1994;33:597-601.

4 Navicharern P, Rhodes M, Flook D, Lawrie B. Endoscopic retrograde cholangiopancreatography (ERCP) and stent placement in the management of large common bile duct placement in the management of large
stones. Aust NZ $\mathcal{F}$ Surg 1994;64:840-2.

5 Van Steenbergen W, Pelemans W, Fevery J. Endoscopic biliary endoprosthesis in elderly patients with large bile duct stones: long-term follow-up. F Am Geriatr Soc 1992;40:57-60.

6 Maxton DG, Tweedle DEF, Martin DF. Retained common bile duct stones after endoscopic sphincterotomy: tempo- three treatment-related deaths during the study, two from cholangitis and one from pancreatitis. None of these patients was under the age of 75 years. In addition, there were four deaths due to unrelated causes (two from acute myocardial infarction, one from bronchopneumonia, and one from ruptured abdominal aortic aneurysm). No death occurred in the patient group stented as a temporising measure.

\section{Discussion}

The first reports of biliary stenting for common bile duct stones appeared in the literature in $1984 .^{16}{ }^{17}$ Over the last five years stenting has increasingly been reported as an appropriate treatment for common bile duct stones, especially in the elderly. ${ }^{2-7} 18$

Our data suggest that endobiliary stents can be employed with an acceptable complication rate. The preponderance of women in the study group is in keeping with other study data ${ }^{2-8} 19$ and probably reflects the greater propensity for women to develop cholelithiasis and choledocholithiasis. Men were significantly more likely to experience complications than women, however, although no other risk factors for complications were identified. It may be that men with calculous disease are more likely to be symptomatic. Whilst there was no significant difference in the incidence of complications in those aged 75 years or less compared with those over the age of 75 years, treatmentrelated deaths were confined to patients over the age of 75 . All of these patients had been stented as definitive therapy. Further, this group of patients had a high mortality rate from unrelated causes, this reflecting the high prevalence of comorbid conditions.

Based upon our findings, a treatment policy has been instituted. Physiologically fit patients of age 75 years or less are stented as a temporising measure only. If duct clearance cannot be achieved at second ERCP six weeks after the initial procedure, the stent is changed and surgery undertaken. We do not recommend long-term stenting in this group as it leaves the patients at permanently increased risk of complications. Patients over the age of 75 years and patients deemed physiologically unfit are stented as definitive treatment.

rary and longterm treatment with biliary stenting. Gut 1995;36:446-9.

7 Lauri A, Davidson BR, Horton R, Burroughs A, Dooley JS. Longterm follow-up of biliary stents for retained common bile duct stones in elderly patients. $\mathcal{F} R$ Coll Surg Edin 1995; 40:42-5.

8 Vellacott K, Powell P. Exploration of the common bile duct: a comparative study. Br f Surg 1979;66:389-91.

9 Cotton PB. Endoscopic management of bile duct stones (apples and oranges). Gut 1984;25:587-97.

10 Cairns SR, Dias L, Cotton PB, Salmon PR, Russell RCG. Additional endoscopic procedures instead of urgent surgery for retained common bile duct stones. Gut 1989;30:535-40

11 Vaira D, Ainley C, Williams S, et al. Endoscopic sphincterotomy in 1000 consecutive patients. Lancet 1989;ii:431.

12 Dowsett JF, Vaira D, Polydorou A, et al. Interventional endoscopy in the pancreatobiliary tree. Am $\mathcal{f}$ Gastroenterol 1984;79:50. 
13 Davidson BR, Neoptolemus JP, Carr-Locke DL. Endoscopic sphincterotomy for common bile duct calculi in patients with gallbladder in-situ considered unfit for surgery. Gut 1988;29:114-20.

14 Martin DF, McGregor JC, Lambert ME, Tweedle DEF. Stone extraction after endoscopic sphincterotomy - an Stone extraction after endoscopic sphin
active policy is best. Gut 1986;27:A1360-1

15 Neoptolemus JP, Davidson BR, Shaw DE, Lloyd D, Carr-Locke DL, Fossard DP. Study of common bile duct exploration and endoscopic sphincterotomy in a consecutive series of 438 patients. Br f Surg 1987;74:916-21.
16 Siegel J, Yatto R. Biliary endoprosthesis for the management of retained common bile duct stones. Am $\mathcal{f}$ Gastroenterol 1984;79:50-4.

17 Forbes A, Leung J, Cotton PB. Endoscopic biliary endoprosthesis for large bile duct stones. Gut 1984;25:A1186-7.

18 Rao KJM, Varghese NM, Blake H, Theodosi A. Endoscopic biliary stenting in a district general hospital. Gut 1995;37: 279-83.

19 Warwick DJ, Thompson MH. Six hundred patients with gallstones. Ann R Coll Surg Engl 1992;74:218-21.

\section{Images in medicine}

\section{Diskitis}

A 70-year-old man was admitted to the hospital because of lumbar pain and sweats. Thirty years earlier, he had had a spine trauma resulting in vesical sphincter dysfunction necessitating intermittent urethral catheterization. Six months before entry, he was treated for septicaemia secondary to an urethrotomy for stricture. During the current hospitalisation, his temperature rose to $38^{\circ} \mathrm{C}$ and blood cultures yielded colonies of Streptococcus milleri. Magnetic resonance imaging of the lumbar spine showed decreased $\mathrm{T} 1$-weighted signals of L2 and L3 vertebral bodies (figure, A) but an increased T2-weighted signal of the intervertebral disk (figure, B). These images, reflecting

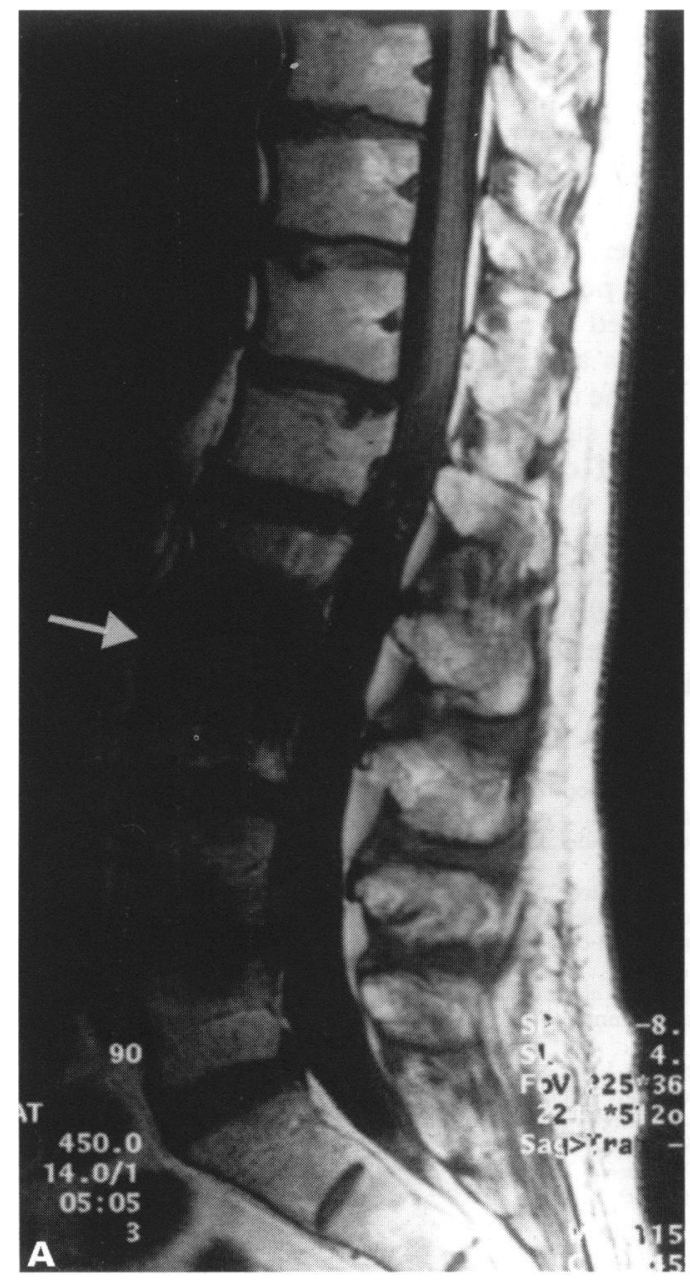

an increase in water content, were consistent with a diagnosis of diskitis. Needle biopsy of the disk confirmed the presence of $S$ milleri. Pathophysiology can be explained by the previous septicaemia and/or the urinary tract manipulation, making possible a spread of the infection through Batson's plexus, a perivertebral valveless system in communication with pelvic veins.

JULIAN DONCKIER ETIENNE DELGRANGE

Department of Internal Medicine and Endocrinology University Hospital UCL of Mont-Godinne 5530 Yvoir, Belgium

Accepted 24 October 1997

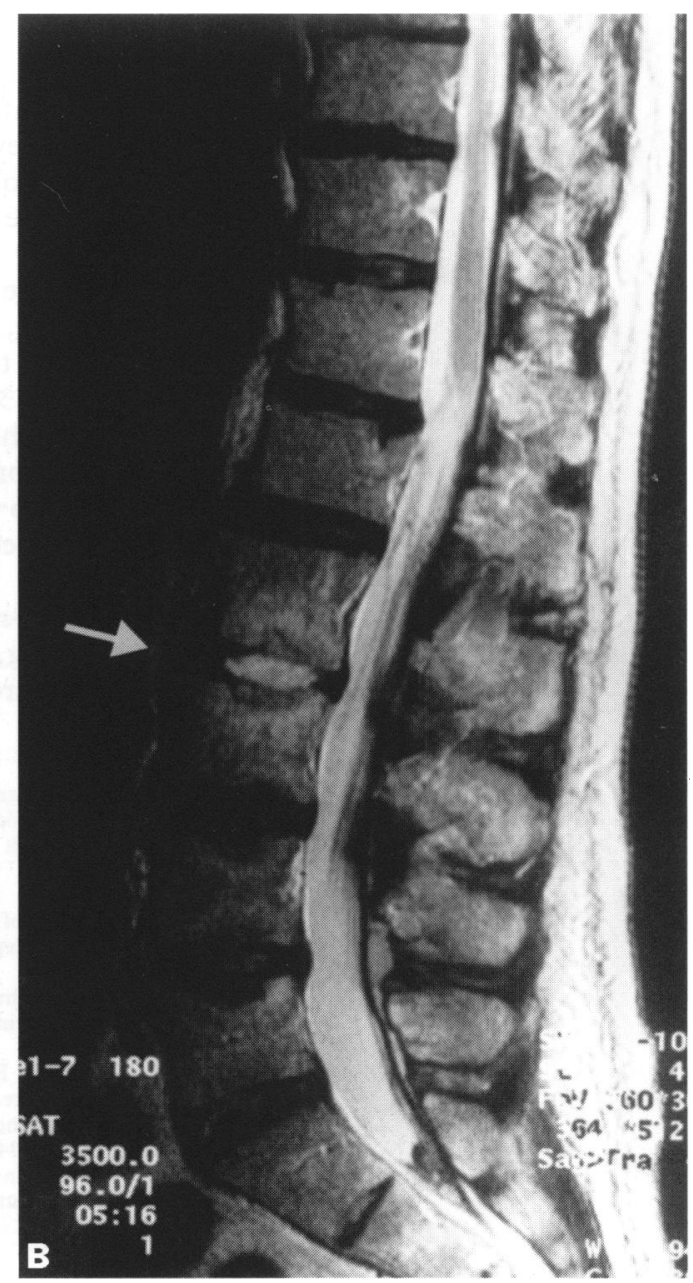

